\title{
Debaixo do Tapete: A Violência Política de Gênero e o Silêncio do Conselho de Ética da Câmara dos Deputados
}

\author{
Tássia Rabelo de Pinho' \\ 0000-0003-1451-2237 \\ 'Universidade Federal da Paraíba, João Pessoa, PB, Brasil. 58051-900 - \\ gabinete@reitoria.ufpb.br
}

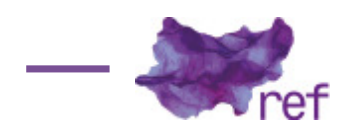

Resumo: O debate sobre a violência contra as mulheres na política tem ganhado força em âmbito internacional. No Brasil, entretanto, esta se mantém invisibilizada, mesmo diante de casos emblemáticos que seguem se multiplicando. Considerando tal lacuna no debate acadêmico e também social, as denúncias realizadas por parlamentares mulheres em relação aos abusos sofridos no Congresso Nacional, e casos amplamente noticiados pela mídia que se enquadrariam na tipologia de violência política de gênero apresentada neste artigo, buscou-se compreender o papel exercido pelo Conselho de Ética e Decoro da Câmara dos Deputados diante de representações abertas em função de denúncias de violência política de gênero. A pesquisa foi realizada por meio do levantamento da participação das mulheres no referido Conselho, e da análise dos encaminhamentos dados às denúncias supracitadas.

Palavras-chave: violência política de gênero; Câmara dos Deputados; conselho de ética; representação política; exclusão.

Under the Rug: Gender-based Violence and the Silence of the Ethics Council of the Brazilian House of Representatives

Abstract: The debate about violence against women in politics has gain strength at the international level, in Brazil, however, it remains invisible, even in the face of emblematic cases that have been multiplying. Considering the almost absence of this theme in the academics and social debate, the cases dispensed by parliamentarians women in relation to abuses suffered, this article objective was to investigate the role of the Council of Ethics of the Chamber of Deputies in Brazil. The analysis was based in representations open according to the denunciations of political violence of gender, and the research was carried out by surveying the participation of women in that Council and the results for the aforementioned denunciations.

Keywords: Gender-based violence; Chamber of deputies; Ethics council; Political representation; Exclusion.

\section{Introdução}

Ao constituir-se um governo - integrado por homens que terão autoridade sobre outros homens -, a grande dificuldade está em que se deve, primeiro, habilitar o governante a controlar $\circ$ governado e, depois, obrigá-lo a controlar-se a si mesmo. A dependência em relação ao povo é, sem dúvida, o principal controle sobre o governo, mas a experiência nos ensinou que há necessidade de precauções suplementares (James MADISON; Alexander HAMILTON; John JAY, 1985, p. 322).

Segundo a teoria da separação de poderes presente em Charles de Montesquieu (1985) e nos escritos Federalistas (1985), dada a tendência à conversão do exercício do poder em 
arbitrariedade, este deve ser limitado pela contraposição entre a ação de distintos poderes. Este princípio é aplicado por meio de medidas constitucionais que visam assegurar a autonomia do Executivo, do Legislativo e do Judiciário de forma a possibilitar o controle mútuo, e evitar que interesses particulares redundem em acúmulo de poder. No Brasil, em que pese a separação de poderes seja cláusula constitucional pétrea, acontecimentos recentes reacenderam o debate sobre a real capacidade de o poder Legislativo exercer sua necessária autonomia em relação ao Executivo.

Em 2017 a Câmara dos Deputados foi duas vezes instada a decidir se o então atual titular da Presidência da República, Michel Temer, deveria ou não ser alvo de investigações resultantes de denúncias movidas pela Procuradoria-Geral da República. Nas duas ocasióes a referida Casa decidiu que Temer só poderia ser investigado quando deixasse o cargo que ora ocupava.

A robustez dos indícios presentes nas denúncias de organização criminosa e obstrução de justiça e as acusações de parlamentares que afirmavam que Temer comprava votos a seu favor no interior na Câmara trouxeram à tona o debate sobre a incapacidade do Legislativo brasileiro de cumprir sua função de fiscalizar as ações do Executivo' e a existência de uma possível relação de compadrio entre os atores políticos que deturparia a função das instituições visando à proteção entre pares.

Se o caso de Temer, Chefe do Poder Executivo, expôs ao mesmo tempo o déficit do funcionamento dos pesos e contrapesos no sistema político brasileiro e o corporativismo de parte expressiva dos mandatários, cabe questionar como são analisadas denúncias que envolvem políticos de um mesmo Poder.

Assim, pretende-se realizar uma análise exploratória sobre as seguintes questões: de que maneira os deputados que integram o Conselho de Ética e Decoro da Câmara dos Deputados encaminham as denúncias movidas contra seus colegas? E as mulheres, minoria absoluta no Parlamento Brasileiro, têm seus direitos respeitados e suas denúncias apreciadas de maneira devida? A análise desta segunda questão levará em consideração as recentes abordagens sobre o conceito de violência política de gênero, que será debatido em sessão dedicada a esta temática.

\section{Metodologia}

Por meio da observação dos dados disponibilizados pelo Centro de Documentação e Informação da Câmara dos Deputados (Cedi), foi possível acessar a composição do Conselho de Ética e Decoro da Câmara dos Deputados ao longo dos anos abarcados pela pesquisa, o que possibilitou a análise da participação das mulheres no mesmo. A partir do sítio da Câmara dos Deputados, que dispõe de parte expressiva dos processos abertos desde $2002^{2}$ - cento e cinquenta representações -, bem como seus encaminhamentos, no presente artigo mapeou-se a apresentação de denúncias no referido Conselho entre os anos de 2002, meses após sua criação, e 2018.

Considerando o recorte deste artigo e o tratamento conferido pelo Conselho de Ética aos casos de violência política de gênero, as representações instauradas no Conselho foram classificadas a partir da conceituação de violência política de gênero proposta por Mona Krook e Juliana Sanín (2016), que engloba a violência física, psicológica, econômica e simbólica. Desta maneira, nem todas as representações apresentadas por mulheres foram consideradas enquanto violência de gênero - esta classificação se circunscreveu a casos de agressões, ameaças, diferentes tipos de assédio, estigmatização, exposição da vida sexual e afetiva, restrições à atuação e à voz das mulheres, entre outros que fossem condizentes com a base teórica mobilizada.

\section{A Violência Política de Gênero}

Antes de adentrar o debate sobre a violência de gênero, faz-se necessário precisar o próprio conceito de gênero. Este, que é fundamental para a teoria feminista e queer e tem sido alvo, no Brasil, de ataques que utilizam a ignorância e a deturpação como armas numa verdadeira cruzada fundamentalista, poderia, de maneira sintética, ser definido como um conceito que

\footnotetext{
' Em contraposição a este argumento poder-se-ia mencionar que este mesmo Congresso Nacional não hesitou em depor uma Presidenta da República, e que esse seria um indício de cumprimento de sua função fiscalizatória. Entretanto, tal assertiva cometeria o equívoco de desconsiderar que a presidenta Dilma Rousseff se encontrava em uma situação que poderia ser definida como de "lame duck". De maneira precisa, esta categoria se remete a governantes cujo sucessor já foi eleito, mas sua consequência é a mesma vista no caso de Dilma que, tal como o governante com sucessor, sofria com a diminuição contínua de sua influência junto a outros políticos durante aquele que, muito provavelmente, seria um limitado tempo à frente do governo. Não se tratava, portanto, de uma ação fiscalizatória, mas da escolha da maior parte do Legislativo de formar uma coalizão junto ao Chefe do Executivo que viria em detrimento daquela que, no momento, atuava no Palácio do Planalto.

${ }^{2}$ Neste trabalho foram analisados todos os casos disponibilizados pelo site da Câmara entre 2002 e abril de 2018 . As ausências identificadas em função das descontinuidades na numeração foram listadas e solicitadas junto ao setor responsável na Câmara dos Deputados. Este, apesar de ter confirmado o recebimento da demanda, até a data do envio deste artigo, ainda não havia dado retorno em relação ao conteúdo solicitado.
} 
expõe que características apresentadas como femininas ou masculinas tratam-se, na verdade, de construções sociais e que, portanto, sofrem alterações em diferentes culturas e períodos históricos. Ao afastar qualquer tipo de essência que determine o que cada gênero é, não afirma a inexistência de diferenças de conformação biológica, mas sim que estas não definem e muito menos explicam o modo como as pessoas agem no mundo.

Os modelos que se constroem, então, tanto do homem quanto da mulher deverão corresponder às funções esperadas desses sujeitos aos quais foram atribuídos papéis específicos. Enquanto o homem aparece através de uma figura forte, disciplinadora, isento de instintos, emoções e sensibilidade, a mulher vai surgir através de uma imagem sensível, fiel, honesta, instintiva, generosa, perspicaz, garantindo-se essa ambivalência através de um pacto de dominação, na medida em que tanto um como o outro incorpora em suas práticas, o discurso enunciado desse domínio expresso nos valores contrários fragilidade/força (Maria Luzia Miranda ÁLVARES, 2003, p. 3).

Trabalhos fundacionais da teoria feminista como O segundo sexo, de Simone de Beauvoir (1980), contribuíram para a construção desta nova perspectiva na qual a mulher deixava de ser encerrada em seu corpo, e os entraves à participação feminina no espaço público passavam a ser considerados enquanto construções sociais ao invés de dados da natureza. Desta maneira, nesse debate se questionou o conhecimento naturalizado do sexo e a consequente normatização da sexualidade, apresentando-os enquanto mecanismos limitados, violentos e opressores que definiam o que é ou não aceitável.

Por meio da compreensão do gênero enquanto constructo foi possível identificar como a distinção entre o masculino e o feminino esteve diretamente relacionada à imposição de um lugar de subordinação às mulheres. Assim como afirma Joan Scott (1986), o gênero não se trata apenas de uma percepção sobre as diferenças sexuais, mas da hierarquização destas. Tal caracterização hierárquica que confere ao homem a posição de mando e à mulher a de submissão, estabelece também formas de violência específicas contra as mulheres, cujo diferencial reside na impossibilidade de compreensão deste fenômeno sem que se leve em consideração a relação entre a sua motivação e o gênero da vítima.

A violência doméstica é a sua mais conhecida expressão. Tendo sido durante muito tempo associada à agressão física cometida contra mulheres na qual o agressor é o marido, sua conceituação no Brasil adquiriu contornos mais amplos a partir da promulgação da Lei Maria da Penha (BRASIL, 2006).

Segundo a referida legislação, a violência doméstica é: "qualquer ação ou omissão baseada no gênero que lhe cause morte, lesão, sofrimento físico, sexual ou psicológico e dano moral ou patrimonial" (BRASIL, 2006, art. 5\%). Esta, portanto, passou a ser compreendida como um rol mais amplo de violências que atinge as mulheres e se estrutura em relações íntimas de afeto, indo além da agressão por parte do cônjuge, incluindo ex-parceiros, namorados e familiares.

Ao dar visibilidade a outras modalidades de violência sofridas pelas mulheres, a Lei Maria da Penha contribuiu não apenas para o enfrentamento a estas no âmbito doméstico, mas também para o debate público sobre outras modalidades de violência às quais as mulheres são expostas e que comprometem sua participação igualitária na sociedade. Neste trabalho o foco está voltado para um tipo particular e pouco debatido de violência contra as mulheres, a violência política de gênero.

No Brasil, apenas recentemente iniciou-se um processo vigoroso de desnaturalização da violência doméstica, e com a Lei Maria da Penha, que ainda não completou 15 anos de existência, esta deixou de ser tratada como algo de caráter privado, no qual o Estado não deveria ter ingerência. A violência contra as mulheres na política brasileira, entretanto, segue sendo naturalizada e, tal como antes ocorria com a violência doméstica, não é sequer reconhecida como tal. Na América Latina, porém, este conceito tem se desenvolvido de maneira potente, tendo inclusive sido positivado em alguns ordenamentos jurídicos na região.

Neste aspecto, o país pioneiro foi a Bolívia que, em 2012, aprovou legislação que tipificou como crime o assédio e a violência política contra mulheres. No mesmo ano, proposição legislativa similar foi apresentada no Equador; esta, contudo, não teve o mesmo sucesso que a boliviana, tendo sido arquivada sob o argumento de redundância em relação à proposta de reforma do Código Penal que reconhecia o crime de assédio político, ainda que este não considerasse a dimensão de gênero. Em 2013, um Projeto de Lei que trazia elementos tanto da proposta boliviana quanto da equatoriana foi apresentado na Costa Rica. No México, a criminalização de atos de violência física, psicológica e sexual perpetrados contra mulheres com o objetivo de impedir sua atuação política foi proposta por meio da reforma da Lei sobre o Acesso das Mulheres a uma Vida Livre de Violência e do Código Federal Eleitoral. Após ter sido aprovada por unanimidade no Senado em 2013, não foi retomada na Câmara dos Deputados (KROOK; SANÍN, 2016).

Em 2013, no Congresso Nacional do Peru, foi apresentada legislação que não mencionava o termo violência, mas visava combater o assédio político contra as mulheres. Enquanto a proposta segue tramitando no Legislativo, foi aprovado o "Plan Nacional contra la Violencia de Género" 
que, em seu Decreto n. 8, define 16 modalidades de violência, dentre as quais está o "assédio político", que consiste em qualquer ação, conduta ou omissão baseada no gênero, cujo objetivo ou resultado seja menosprezar, anular, impedir, obstaculizar ou restringir os direitos políticos das mulheres (Flávia BIROLI, 2016).

Em artigo que faz um apanhando do debate na literatura e nas legislações nacionais referentes à violência política de gênero, Krook e Sanín (2016) apontam que grande parte dos estudos sobre a temática tem se aproximado da definição presente na legislação boliviana que prevê três tipos de manifestações de violência política de gênero: física, sexual e psicológica. Segundo as autoras, esta interpretação tem levado a categoria de violência psicológica a abarcar um sem número de comportamentos que, para elas, poderiam ser reconhecidos enquanto formas distintas de violência. Desta maneira, sugerem a inclusão das categorias de violência simbólica e econômica, sem excluir a possibilidade de interseção entre essas diversas formas.

Precisamente, propõem uma definição estendida de violência política de gênero que integre violências sexuais à categoria de violência física, e separe a categoria violência psicológica em econômica, simbólica e psicológica. Apontam que estas diversas formas de violência política de gênero se distinguem de outros atos de violência, inclusive no âmbito da política, por ter como objetivo impedir a participação de uma mulher como mulher, não como indivíduo, membro do partido ou defensora de determinada posição ideológica.

De acordo com a definição que apresentam, a violência física compreenderia atos que afetam a integridade física de uma mulher ou de membros de sua família visando atacá-la, e, tal como exposto, abrange a violência sexual. A violência psicológica seria aquela que causa danos no estado mental ou emocional, incluindo ameaças de violência física, bem como atos destinados a prejudicar socialmente a mulher em questão.

A violência econômica na política é definida como atos que buscam controlar o acesso ou o comportamento das mulheres na esfera política, restringindo sistematicamente o acesso a recursos econômicos que, de outra forma, estão disponíveis para os homens. O objetivo é tornar o trabalho político tão difícil ou frustrante que as mulheres sejam levadas a se retirar por conta própria ou a reduzir as chances de que elas possam realizar seu trabalho de maneira eficaz, afetando assim suas futuras carreiras políticas.

A definição de violência simbólica das autoras ancora-se na de Pierre Bourdieu (2007), que a concebe como uma disciplina usada contra outrem para confirmar sua posição na hierarquia social. A violência simbólica contra as mulheres na política procuraria deslegitimá-las por meio de estereótipos de gênero que lhes negam competência na esfera política. Para estas autoras, o tratamento negativo se converte em violência quando implica desrespeito fundamental à dignidade humana, como produzir e distribuir imagens altamente sexualizadas e pejorativas, usar as mídias sociais para incitar atos violentos, ou não reconhecer ou negar explicitamente a existência de uma mulher nos espaços políticos pelo simples fato de ser mulher.

Esta tipologia distingue os tipos de violência sem deixar de incorporar o fato de que manifestações específicas podem estar inter-relacionadas, dado que a um ato podem ser atribuídos múltiplos significados, em função de suas diferentes possibilidades de experimentação ou interpretação.

Outro esforço importante do debate realizado por essas autoras consiste em buscar precisar o conceito de violência política de gênero por meio da distinção em relação à violência eleitoral. Tanto homens quanto mulheres podem ser vítimas de atos violentos ou ameaças que visem influenciar o processo eleitoral; logo, nem todos os casos de violência eleitoral são orientados pelo gênero da vítima, e mesmo que os casos de violência política de gênero possam ocorrer no contexto das eleições, estes não se limitam a este período. Assim, Krook e Sanín (2016) afirmam que:

Violence against women in politics, we contend, is a subset of violence against women and is slightly distinct from violence against women in elections. Whereas the latter includes acts during electoral periods directed at women as candidates, voters and activists, violence against women in politics is perpetrated against female politicians, during electoral campaigns but also afterwards as women assume political positions. It is vital to recognize at the outset that in all states candidates and elected officials do and should face criticisms and challenges related to their policy ideas and performance. Freedom of expression, moreover, is a central element in a healthy democratic society. However, we argue, certain behaviors "cross the line" from free speech to violence when they are directed at women as women with the purpose of leading them to withdraw from politics. As such, while inflicted on a particular woman, these actions are, in effect, directed at all women (p. 136).

Apontam ainda que quando mulheres na política são atacadas em função dos seus posicionamentos políticos não se trata de violência política contra as mulheres. Entretanto, se estes ataques são voltados ao corpo da mulher, ou relacionados a estereótipos de gêneros tal como questionamento a papéis sociais tradicionais, ou outros meios com vias a negar sua competência 
na esfera política, apresentam ambiguidades que podem vir a enquadrá-los enquanto violência política de gênero.

Para além da forma e do objetivo, a violência política de gênero se diferencia dos ataques violentos cometidos por oponentes em meio ao embate político, em função de sua origem mais difusa. Estes podem advir de setores da política como colegas e líderes da oposição, mas também da sociedade de maneira mais ampla, da família, dos amigos, da comunidade, de líderes religiosos, bem como da mídia, entre outros (PEACEWOMEN, 2006).

A violência contra as mulheres na política pode ter um impacto que vai além das mulheres que a sofrem diretamente, dado que cumpre o duplo papel de buscar alijar aquela que é alvo das agressões da política e diminuir o alcance de sua atuação, bem como passar uma mensagem para todas as outras mulheres que indique que a esfera pública não é o seu lugar, e caso insistam em disputá-lo, sofrerão sanções por tal comportamento. Assim, a análise do tratamento dado a esse tipo de violência no âmbito da Câmara dos Deputados, mais alto espaço eletivo proporcional do Brasil, é importante para a compreensão mais geral dos diversos limites impostos às mulheres na política.

\section{O Conselho de Ética e Decoro da Câmara dos Deputados}

O Conselho de Ética e Decoro Parlamentar foi criado em outubro de 2001. Sua principal função é cuidar do procedimento disciplinar destinado à aplicação de penalidades em casos de descumprimento das normas relativas ao decoro parlamentar no âmbito da Câmara dos Deputados.

Segundo o Art. $4^{\circ}$ do Código de Ética e Decoro Parlamentar da Câmara dos Deputados (BRASIL, 2015a), constituem procedimentos incompatíveis com o decoro parlamentar: abusar das prerrogativas constitucionais asseguradas aos membros do Congresso Nacional; perceber, no exercício da atividade parlamentar, vantagens indevidas; celebrar acordo que tenha por objeto a posse do suplente, condicionando-a à contraprestação financeira ou à prática de atos contrários aos deveres éticos ou regimentais dos Deputados; fraudar o regular o andamento dos trabalhos legislativos para alterar o resultado de deliberação; omitir intencionalmente informação relevante ou prestar informação falsa; e praticar irregularidades graves no desempenho do mandato ou de encargos decorrentes, que afetem a dignidade da representação popular.

O Art. $5^{\circ}$ aponta ainda que atentam contra o decoro parlamentar condutas que perturbem a ordem das reuniões da Câmara, infrinjam suas regras de boa conduta, bem como a prática de ofensas físicas ou morais nas dependências da Casa. Também é passível de sanção o desacato a outro parlamentar, à Mesa ou Comissão ou os respectivos Presidentes; o uso dos poderes e prerrogativas do cargo para constranger ou aliciar servidor, colega ou qualquer pessoa sobre a qual exerça ascendência hierárquica, com o fim de obter qualquer espécie de favorecimento; a revelação de conteúdo de debates, deliberações ou documentos que a Câmara dos Deputados ou Comissão tenham resolvido que devam ficar secretos; o uso de verbas de gabinete ou qualquer outra inerente ao exercício do cargo em desacordo com os princípios fixados pela Constituição; relatar matéria submetida de interesse específico de pessoa física ou jurídica que tenha contribuído para o financiamento de sua campanha eleitoral; e fraudar o registro de presença às sessões ou às reuniões de Comissão.

O Conselho de Ética é composto por 21 membros titulares e igual número de suplentes, com mandato de dois anos, que não podem ser substituídos em nenhum momento. Deve atuar no sentido da preservação da dignidade do mandato parlamentar; processar os acusados; instaurar processo disciplinar e proceder todos os atos necessários à sua instrução; e responder às consultas formuladas pela Mesa, Comissões, Partidos Políticos ou Deputados sobre matérias relacionadas ao processo político-disciplinar.

As penalidades aplicáveis por conduta atentatória ou incompatível com o decoro parlamentar podem ser de quatro tipos: censura verbal ou escrita; suspensão de prerrogativas regimentais por até seis meses; suspensão do exercício do mandato por até seis meses; e perda de mandato (BRASIL, 2002, Art. 10).

O Conselho atua mediante provocação da Mesa Diretora da Câmara dos Deputados para a instauração de processo disciplinar. Esta pode receber pedidos de instauração de representação em face de Deputado Federal de outros parlamentares, Comissões e cidadãos em geral. Partidos políticos com representação no Congresso Nacional também podem encaminhar representação à Mesa Diretora, que, neste caso, tem a obrigação de enviá-la diretamente ao Conselho de Ética.

Assim, o caminho mais rápido e certo - dado que não abre espaço para qualquer discricionariedade por parte da Mesa Diretora - para a instauração de um processo é por meio da apresentação de representação assinada por Partidos Políticos, o que faz com que este seja o procedimento mais utilizado. Dessa maneira, mesmo que ampla maioria dos pedidos seja iniciada por via partidária, na prática, muitos casos tratam-se de processos abertos a pedido dos próprios parlamentares contra os seus colegas, o que significa dizer que nem todos seriam beneficiários de 
uma postura que visasse à impunidade generalizada, pois os autores das denúncias se considerariam prejudicados.

Desta feita, seria possível concluir que, não havendo decisões isentas de gerar contrariedade em alguma das partes, estas variariam de acordo com o conteúdo das denúncias. Entretanto, há elementos que indicam que determinados setores podem estar sendo sistematicamente prejudicados pelas decisões tomadas no Conselho. Neste ponto, Madison (In MADISON et al., 1985) podem contribuir para a explicitação do raciocínio em curso.

Em um de seus artigos, este autor expôs sua preocupação com a possibilidade de que alguns interesses viessem a controlar o poder com vias a promover os objetivos de determinada facção. Desta maneira, alertou que o princípio majoritário, base dos governos populares, poderia representar uma ameaça aos direitos das minorias, preocupação também partilhada por Alexis de Tocqueville (2004). ${ }^{3}$

Dado que as facções não poderiam ser eliminadas sem levarem consigo o direito à liberdade expressão, a solução, para Madison et al. (1985), seria deixar a cargo da pluralidade de facções representantes de diversos interesses a tarefa de impedir que parte desses se sobrepusesse aos demais de maneira tirânica. Sendo composta por 89,3\% de homens (IPU, 2018), na Câmara dos Deputados, tal pluralidade inexiste no quesito gênero, e como será visto, tampouco no Conselho de Ética.

Dados levantados pela presente pesquisa apontam que o Conselho de Ética se mostrou ainda menos permeável às mulheres do que o conjunto da Câmara dos Deputados. Este, além de jamais ter sido presidido por uma parlamentar, contou historicamente com uma participação diminuta das mesmas em sua composição.

Entre a $51^{a}\left(2001^{4} / 2003\right)^{5}$ e a $55^{a}(2015 / 2019)$ legislatura em curso durante a realização da pesquisa, 267 parlamentares diferentes ocuparam cadeiras do Conselho de Ética da Câmara, dentre os quais 151 na condição de suplentes e 118 na de titulares. Ao longo de um período que compreende quase duas décadas, 12 suplentes eram mulheres e, dentre os titulares, apenas 9 não eram do sexo masculino.

Quando comparado com a atual representação de mulheres nas duas Casas do Congresso Nacional, o Conselho de Ética apresenta uma participação feminina ainda mais ínfima, dado que as mulheres titulares representaram na soma das legislaturas pesquisadas apenas $7,7 \%$ do total de integrantes deste Conselho, o que, em se tratando de um universo muito menor, representa, em termos absolutos, a quase completa exclusão das mulheres deste espaço.

Tal como pode ser visto no gráfico abaixo, a observação da composição do Conselho de Ética por legislatura deixa ainda mais nítida a exclusão. Em 2003, ano em que a porcentagem da participação feminina na Câmara passou de 6,8\%, em 2001, para 8,6\%, seu incremento mais considerável ao longo do período analisado, ainda que modesto, o Conselho de Ética da Câmara contou com sua maior representação feminina, $11 \%$. Entretanto, este ano tratou-se de um outlier, pois na legislatura seguinte as mulheres passaram a representar $1 \%$ do Conselho e jamais voltaram a ultrapassar a barreira dos $10 \%$.

Iris Young (2006) sugere que atores mais próximos na esfera social possuem pontos de vista semelhantes, enquanto os socialmente distantes tendem a ver as coisas de modo diverso. Isto significa dizer que a perspectiva trazida pelos parlamentares homens durante a análise de denúncias de violência política contra as mulheres pode negligenciar inúmeros aspectos que teriam mais dificuldades de passarem despercebidos caso também tivessem sido observados por mulheres.

Não se trata de uma defesa da representação descritiva, em que para serem representados os grupos sociais deveriam ter atributos comuns a todos os seus membros, e sim de uma ideia de relacionamento entre os indivíduos de um mesmo grupo social que não determina sua identidade, mas que estabelece compreensões similares sobre os processos sociais que necessitam ser representados no espaço político. As perspectivas sociais são diferentes entre si, mas não incompatíveis, apenas evidenciam aspectos que não estão nítidos para aqueles que partilham de outra perspectiva devido ao seu posicionamento na estrutura social. Trata-se de um ponto de partida para o debate e não uma determinação fechada.

Constatada a exclusão, e considerando que, para Young (2006), a representação de perspectivas sociais se dá por meio da presença da visão de mundo de determinados grupos nas deliberações políticas, na próxima seção, debater-se-á as possíveis consequências desta ausência.

\footnotetext{
${ }^{3}$ É sabido que nem Madison nem Tocqueville, tal como a maioria de seus contemporâneos, expressavam qualquer preocupação com a exclusão política das mulheres. Mobiliza-se aqui seus argumentos em relação à sobreposição das maiorias em relação às minorias, pois ainda que estes não debatam o tema central do presente trabalho, trazem reflexões importantes sobre as limitações ao direito das maiorias quando estas subjugam as minorias.

${ }^{4}$ Os dados disponibilizados iniciam-se a partir da segunda gestão do Conselho de Ética e Decoro da Câmara, por isso não há coincidência com o ano em que a $51^{a}$ legislatura foi iniciada.

${ }^{5} \mathrm{~A}$ posse dos Deputados Federais ocorre em 01 de fevereiro, razão pela qual seus mandatos se estendem até o ano seguinte à eleição que renova os mandatos.
} 


\section{Titulares do Conselho de Ética}

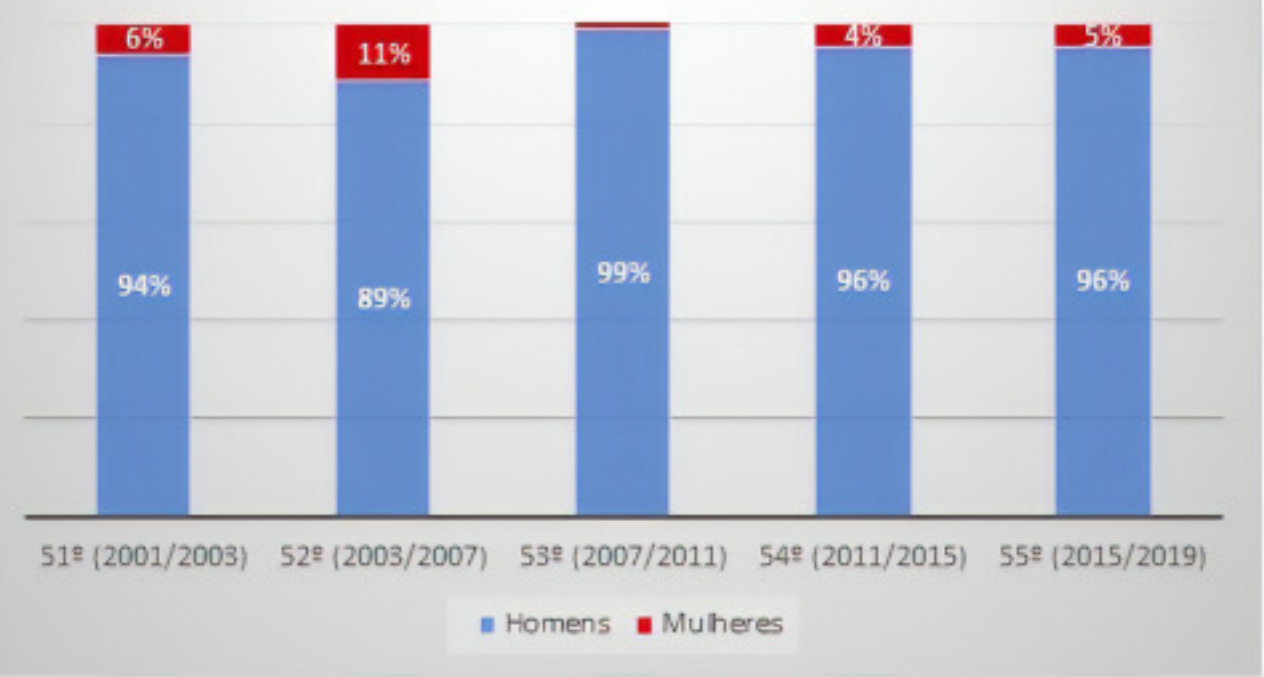

Gráfico 1 - Titulares do Conselho de Ética e Decoro da Câmara dos Deputados por Sexo Fonte: Elaboração própria.

\#PraTodoMundoVer Gráfico de barras com titulares do Conselho de Ética e Decoro da Câmara dos Deputados por Sexo entre 2001 e 2019. 94\% de homens na $51^{\text {a }}$ legislatura (2001 a 2003), $89 \%$ de homens na $52^{a}$ legislatura (2003 a 2007), 99\% de homens na 53a legislatura (2007 a 2011 ), $96 \%$ de homens na $54^{a}$ legislatura (2011 a 2015), 96\% de homens na 55a legislatura (2015 a 2019). Cada legislatura é representada por uma barra vertical em que o azul diz respeito à porcentagem de homens e o vermelho diz respeito à porcentagem de mulheres. As legislaturas estão dispostas abaixo da linha horizontal sobre a qual aparece a porcentagem feminina e masculina de cada uma delas.

Voltar-se-á para o conteúdo das decisões do Conselho de Ética referentes às denúncias de violência política de gênero, objetivando responder às seguintes questões: os direitos das mulheres são respeitados na Câmara dos Deputados? E quando feridos, seus artífices são punidos? Qual o papel exercido pelo Conselho de Ética diante de denúncias de violência política de gênero?

\section{A presença feminina na política brasileira}

Os altíssimos índices de violência doméstica, feminicídio, bem como de agressões e assédio sexual no Brasil indicam que a violência contra as mulheres segue presente em nossa sociedade e se apresenta de maneira multifacetada. Alguns indicadores apontam como esta chaga ainda coloca as mulheres brasileiras em situação de ameaça constante à sua integridade física e psicológica, e estabelece barreiras para que estas tomem parte da sociedade em pé de igualdade com os homens.

Segundo o relatório Global Gender Gap (WORLD ECONOMIC FORUM, 2017), ranking do Fórum Econômico Mundial que analisa a igualdade entre homens e mulheres em 144 países, 0 Brasil, que em 2016 ocupava a $79^{a}$ posição, caiu para a $90^{a}$. Vale destacar que, na primeira edição da pesquisa, realizada em 2006, o Brasil estava em $67^{\circ}$, o que indica um retrocesso mesmo diante de avanços como a promulgação da Lei Maria da Penha e da tipificação do feminicídio no Código Penal.

No que se refere aos indicadores de igualdade de condições no acesso a saúde e educação, foram registradas melhorias modestas, ${ }^{6}$ entretanto, em termos de paridade econômica - segundo o relatório, a renda média da mulher corresponde a 58\% da recebida pelo homem -, e no que diz respeito à representatividade política, o estudo aponta que as mulheres brasileiras seguem enfrentando acentuada discrepância em relação aos homens, elementos que foram decisivos para que o país fosse rebaixado no ranking.

O sub-índice representatividade política "Empoderamento Político" aponta o quanto a participação política das mulheres segue sendo o aspecto mais vulnerável da promoção da igualdade de gênero no Brasil. Neste ponto a queda foi ainda mais acentuada e o país passou da $86^{a}$ posição para $110^{a}$, o que não é de se estranhar, dada a baixíssima representatividade das mulheres no Congresso Nacional e no Executivo Federal. No ranking de participação feminina

${ }^{6}$ Para cada estudante homem do ensino superior brasileiro, as mulheres ocupam 1,4 vaga, e a expectativa de vida feminina é de 67,8 anos, frente a 63,1 anos da masculina. 
nos Parlamentos Nacionais do Inter-Parliamentary Union (IPU, 2018), o Brasil ocupa o $152^{\circ}$ lugar por contar com apenas $10,7 \%$ de mulheres na Câmara dos Deputados e $14,8 \%$ no Senado.

Se a baixa representatividade das mulheres no Legislativo brasileiro é um fenômeno que se perpetua no tempo, no âmbito do Executivo Federal os últimos anos não foram de estagnação, mas de retrocesso. A partir do governo de Michel Temer, as mulheres, que não apenas haviam conquistado espaço no primeiro escalão do Governo Federal como contavam com a Secretaria de Política de Mulheres com status de ministério, foram praticamente alijadas do corpo ministerial.

Até a última semana do Governo da presidenta Dilma Rousseff, dentre os 32 ministérios, seis eram chefiados por mulheres. No início do seu primeiro governo, em 2011 , as mulheres alcançaram sua maior marca à frente dos ministérios, ocupando 10 das 37 pastas. Michel Temer, que assumiu como presidente interino em maio de 2016, na ocasião montou uma equipe de 24 ministros sem nenhuma mulher. Em abril de 2018 seu Governo contava com 29 ministérios, dos quais apenas um tinha uma mulher no comando, a chefe da Advocacia-Geral da União, Grace Maria Mendonça.

A ausência de mulheres em espaços de tomada de decisão contribui para a ideia de que a política não é um lugar destinado à participação feminina, elemento que, combinado a expressões de violência política que menosprezam as mulheres que possuem atuação política, perfaz um quadro que desincentiva outras mulheres a construir uma carreira política.

Durante o processo que golpeou a presidenta Dilma Rousseff, mas também nas últimas campanhas presidenciais, que contaram com mulheres na disputa, as representações na mídia e nas redes sociais apresentaram conteúdos sexistas que foram muito além da mera disputa política. Dilma, que já sofria com processo de deslegitimização de sua imagem enquanto presidenta desde que assumiu o mandato, em 201 1, passou a receber ataques misóginos da pior espécie que a descreviam como desequilibrada e mobilizavam conteúdo sexual violento. Situações que expuseram uma violência bastante específica, cometida contra uma mulher com o objetivo de mostrar que ela, e as mulheres de maneira mais ampla, não seriam qualificadas para 0 exercício da política.

No âmbito do Parlamento, a situação não parece ser diferente. De acordo com o depoimento da Deputada Federal Maria do Rosário, alvo, em 2014, de um dos mais notórios casos de violência política de gênero, quando foi atacada do púlpito da Câmara dos Deputados pelo Deputado Federal Jair Bolsonaro, que sem qualquer pudor afirmou que ela não merecia ser estuprada devido à sua feiúra, a Câmara dos Deputados é um lugar hostil às mulheres:

Na Câmara dos Deputados as parlamentares atuam em um ambiente hostil, em que o desrespeito é comum e a impunidade constante. O Conselho de Ética fecha os olhos às agressões que sofremos e dessa maneira contribui com a perpetuação de uma cultura sexista. É inaceitável, mas a verdade é que somos submetidas à humilhação pública somente por defendermos nossas ideias em mandatos que têm iguais prerrogativas constitucionais, mas que são continuamente desrespeitados (Maria do Rosário NUNES, 2017).

Tal como aponta Charles Taylor (1992), o reconhecimento não se deu da mesma forma para todos. Em nossa sociedade existiriam cidadãos de segunda classe que foram, ou são alijados da cidadania, o que, para este autor, implicaria a necessidade de uma política de reconhecimento. Sua análise dialoga com a ideia de que a exclusão pretérita da mulher e os símbolos com os quais ainda hoje estas são identificadas limitam sua atuação na esfera pública, situação relatada pela senadora Vanessa Grazziotin (2017):

[...] a violência política de gênero alcança uma mulher em qualquer lugar ou espaço em que ela se movimente na sua luta por direitos. Pode ser até num corredor na Câmara, como aconteceu à deputada Maria do Rosário, em 2014, ofendida aos gritos e empurrada por um deputado em flagrante captado por câmera de TV. [...] É preciso dizer que os ataques feitos às parlamentares comportam um tipo de agressividade raramente visto nas provocações que um homem dirige a outro homem, pelo menos na esfera pública. Alguém imagina um humorista postando um vídeo nas redes sociais que o mostra esfregando uma carta na sua cueca e remetendo-a para Michel Temer, para Gilmar Mendes ou para o deputado Jair Bolsonaro? (p. 1).

As agressões mencionadas pela senadora, e outras amplamente noticiadas, podem estar sendo utilizadas no interior da Câmara como mecanismos de silenciamento que se agravariam caso fossem suportadas pela impunidade no âmbito do órgão responsável pela apuração dessas denúncias, debate que será realizado na seção seguinte.

\section{Conselho de Estética?}

Durante o longo debate que culminou com a cassação do ex-Deputado Federal Eduardo Cunha, o Deputado Federal Chico Alencar, conhecido por suas falas irônicas e ácidas, afirmou que, diante de seguidas manobras que impediam o cumprimento de suas funções, o Conselho de Ética e Decoro da Câmara dos Deputados deveria mudar o nome para "Conselho de Estética e Decoração". Ainda que o desfecho do caso que indignou o parlamentar do Partido Socialismo e 
Liberdade (PSOL) tenha sido a perda de mandato do então Presidente da Câmara, a presente pesquisa indica que o destino da maior parte das representações é o arquivamento.

De acordo com os dados disponibilizados pelo site da Câmara dos Deputados, entre 2001 e 2018, o Conselho de Ética recebeu 150 representações, dentre as quais duas foram apensadas (Representação 27 de 2014 apensada a 26 de 2014 e 31 e 32 de 2008 [BRASIL, 2014a, REP 24]) e uma foi desconsiderada em função de perda do objeto (Representação 41 de 2005 foi tornada sem efeito pela aprovação do Parecer do processo 01/2005, referente à Representação n० 28 / 2005 [BRASIL, 2005, REP 28]), totalizando 147 casos. Destes, 120 foram arquivados, sendo que 58 não foram sequer apreciados. Neste amplo, mas pouco eficaz universo, foram classificados enquanto denúncias de violência política de gênero sete casos que serão debatidos abaixo.

A primeira representação classificada como violência política de gênero é a n 36 de 2014 (BRASIL, 2014b, REP 36), impetrada em conjunto pelo Partido dos Trabalhadores (PT), Partido Comunista do Brasil (PC do B), PSOL e Partido Socialista Brasileiro (PSB), em face do Deputado Jair Bolsonaro. Trata-se do já mencionado caso de agressão à Deputada Maria do Rosário que incluía ainda ofensas injuriosas, difamantes e caluniosas contra a deputada e à presidenta Dilma Rousseff. Ambas foram acusadas por Bolsonaro de participarem de atos criminosos.

Por meio da análise da argumentação presente na representação em tela é possível afirmar que, ainda que esta não adentre o debate sobre violência psicológica, uma das modalidades classificadas como violência política de gênero pela legislação boliviana defende que este caso se configura como ameaça, dado que o agressor afirma o crime de estupro enquanto conduta eletiva, cuja decisão sobre sua prática se ancoraria no que chamou de "merecimento" da mulher atribuído por ele.

Segundo o conceito debatido por Krook e Sanín (2016) e a própria lei aprovada na Bolívia, a ameaça de violência sexual estaria dentre as práticas consideradas como violência política de gênero. Segundo destaca Bardall (2013), a sexualidade das mulheres é um símbolo potente, e ameaças de estupro contribuem para crenças de que estas são vulneráveis - e podem ser punidas por atos de agressão sexual. Indo além, afirma ainda que a mobilização de questões referentes à moralidade sexual feminina das mulheres que fazem política não é incomum.

No caso em questão, a defesa apresentou a enorme repercussão negativa, particularmente nas redes sociais, onde a deputada sofreu inúmeras ameaças de estupro e outras modalidades de violência. Entretanto, em que pese sua gravidade, o caso foi arquivado em decorrência do término da legislatura, assim seu mérito sequer foi julgado.

Fora dos muros da Câmara o resultado foi outro. No dia 21 de junho de 2017, o Supremo Tribunal Federal (STF) aceitou a denúncia da Procuradoria-Geral da República (PGR) contra o referido deputado, por injúria e incitação ao estupro. No âmbito do Tribunal de Justiça do Distrito Federal (TJ-DF), o deputado foi condenado em 2015 a pagar indenização de R\$ 10 mil à petista por danos morais, mas recorreu, sem sucesso, pois a Terceira Turma do Superior Tribunal de Justiça (STJ) manteve a decisão por unanimidade.

A segunda representação ao Coética, considerada por esta pesquisa como um caso de violência de gênero, foi a $n^{\circ} 02$ de 2015 , impetrada pelo PC do B em face do deputado Alberto Fraga. Este foi acionado em função de suas falas em plenário, nas quais afirmou que: [...] mulher que bate como homem tem que apanhar como homem também, e em seguida que: [...] mulher que participa da política e bate como homem tem que apanhar como homem também (BRASIL, 2015a, REP 02, p. 2). A representação destaca ainda que, após a Deputada Jandira Feghali ter realizado pronunciamento crítico à manifestação de Fraga, este afirmou que: Aqueles que são mais valentes me procurem logo após aqui (BRASIL, 2015a, REP 02, p. 2), fala considerada ameaçadora por parte dos denunciantes.

O parecer do relator, deputado Washington Reis, defendeu o arquivamento do caso tendo como base o argumento de que a conduta do deputado Alberto Fraga, ainda que devidamente comprovada, não configurava quebra de decoro, pois o representado utilizou as palavras tidas como ofensivas no sentido figurado. ${ }^{7}$ Seu parecer foi aprovado com 14 votos a 3 e o caso foi arquivado.

A representação n 03 de 2015 apresentada pelo PC do B contra o deputado Roberto Freire denunciava que o parlamentar havia agredido fisicamente a deputada Jandira Feghali: agarrando seu braço e forçando-o na direção do chão num gesto de muita violência, machucando seu pulso (BRASIL, 2015b). Apesar de o processo ter contado com fotos e gravações da cena descrita, o partido da deputada retirou a representação dias após a sua apresentação. Segundo declarou o então líder do PC do B, deputado Daniel Almeida: O episódio ocorreu em um ambiente de debate mais intenso. Não houve a intenção do deputado Roberto Freire nem da deputada Jandira de produzir fatos que caracterizassem a quebra de decoro parlamentar (NOBRE, 2016). A Mesa entendeu, entretanto, que esta deveria ser apreciada no Conselho de Ética que designou o deputado Paulo Azi como relator. Em seu relatório, Azi defendeu o arquivamento

\footnotetext{
${ }^{7}$ Parecer preliminar do Deputado Sandro Alex.
} 
que foi aprovado por unanimidade, provavelmente em virtude da tentativa de o partido denunciante de retirar o tema de pauta. De toda maneira, há aspectos deste relatório que valem ser abordados.

O relator iniciou seu exame do caso enaltecendo a figura do representado e, tal como posteriormente faria o deputado Daniel Almeida na fala supracitada, relativizando a possível condição de vítima da deputada Jandira ao afirmar que:

[...] as imagens da TV Câmara capturaram um entrevero verbal entre parlamentares. A protagonista foi a deputada Jandira Feghali, que em sua argumentação pareceu agredir a reputação de um grande homem público, o deputado Roberto Freire, um homem decente e correto, de 73 anos (BRASIL, 2015b, p. 3).

Dando prosseguimento à sua análise, Azi relatou que: O parlamentar pernambucano a segurou pelo braço buscando tirá-la da discussão. Buscando justificar o fato, ele próprio reconhece que Roberto Freire a segurou contra a sua vontade. No parágrafo seguinte o relator, mais uma vez justificando a ação do representado e questionando a da deputada, afirma que: Ali no empurraempurra, para se equilibrar e transitar no aglomerado de parlamentares é até possível que o deputado do PPS tenha tocado ou, até mesmo, puxado o braço de Jandira, que começou a gritar de maneira agressiva [...] (BRASIL, 2015b, p. 3). O parlamentar concluiu seu relatório uma vez mais elogiando a história de Roberto Freire e dizendo que esta não pode ser manchada pelo o que alcunha de: destempero revanchista de quem aparentemente está apenas em busca de holofotes (NOBRE, 2016). O desfecho não apenas não foi a punição daquele que comprovadamente agrediu fisicamente uma parlamentar, como o questionamento à postura da vítima, qualificada como uma destemperada que tinha como objetivo utilizar a situação para obter destaque midiático.

A representação no 10 de 2016 (BRASIL, 2016) apresentada pelo PT em face do deputado Laerte Bessa denunciava o pronunciamento proferido por ele em 15 de junho de 2016, no qual este chamou a presidenta Dilma de vagabunda. Segundo argumentaram os proponentes da representação, ao se dirigir à presidenta de maneira injuriosa, pejorativa e machista, Bessa incorreu em prática discriminatória, bem como ofendeu a todas as mulheres.

Em seu relatório, o deputado Mauro Lopes afirmou que, apesar da existência de indícios suficientes de autoria e prova da conduta relatada pelos denunciantes, o fato não era atentatório ao decoro parlamentar, dado que, para ele, ofensas e xingamentos representam elementos do debate político. Concluiu seu voto pelo arquivamento, que contou com 8 votos favoráveis a 4 contrários, argumentando que:

[...] não fica evidenciado que sua fala tenha sido um ataque de gênero na figura da exPresidente Dilma. Feita sua devida contextualização, mostra-se de forma indubitável, que o sentido conferido ao seu pronunciamento foi o de demonstrar a sua indignação com a gestão da coisa pública (BRASIL, 2016, p. 5).

De acordo com o conceito trabalhado nesse artigo, a violência política de gênero consiste em comportamentos que têm como alvo específico as mulheres que atuam politicamente, em sua condição de mulheres, e visa fazer com que estas abandonem a política ou sejam deslegitimadas aos olhos do público. Diferente do que afirmou o relator, o xingamento à Dilma não se referia em momento algum à sua forma de gerir a coisa pública, mas sim à sua condição de mulher, dado que o termo utilizado sequer possui o mesmo significado quando utilizado em referência aos homens.

Os ataques sistemáticos e difusos à Deputada Maria do Rosário também podem ser considerados enquanto violência política de gênero, sendo a denúncia contida na representação n० 18 de 2017 (BRASIL, 2017) um exemplo de um dos mecanismos apontados como tendo destaque nesse tipo de prática: os ataques voltados às famílias das mulheres.

No início do ano de 2017, um blog anônimo divulgou fotos íntimas da filha adolescente da Deputada Maria do Rosário. Ao término deste mesmo ano, o Deputado Federal Jorge Solla denunciou que o Deputado Federal Wladimir Costa havia divulgado uma destas fotos no grupo de WhatsApp da Comissão de Fiscalização Financeira e Controle da Câmara dos Deputados, com uma montagem que comparava a adolescente com os filhos de Jair Bolsonaro. Segundo o denunciante: Com o propósito veemente de atacar a condição de mulher, mãe e parlamentar da Deputada Federal Maria do Rosário (BRASIL, 2017). O relator do caso, deputado João Marcelo, apresentou parecer pelo arquivamento por considerar que a autoria e materialidade dos fatos narrados não estavam comprovadas, pois o denunciado apresentou documento que, segundo 0 relator, comprovava que o número que enviou as fotos não era seu.

Tal argumento foi contestado pelo voto em separado apresentado pelos Deputados Leo de Brito e Valmir Prascidelli. Neste, os parlamentares defenderam a tese de que a mera declaração da operadora de telefonia de que o número cadastrado não estava em nome de Wladimir Costa não afastaria peremptoriamente sua responsabilidade, dado que o número poderia estar em nome de assessores ou familiares, hipótese que não foi investigada. Destacaram ainda que o relatório de João Marcelo desconsiderou que em outras ocasiões o detentor deste mesmo número realizou 
posts - anexados ao voto em separado - que contavam com a assinatura do deputado. A despeito de tal contestação, o relator não alterou seu parecer, que foi aprovado por 9 votos favoráveis e 4 contrários. A matéria foi arquivada.

A mais recente representação protocolada no Conselho de Ética, 26 de 2018 (BRASIL, 2018), classificada como violência política de gênero, refere-se às declarações de Alberto Fraga em relação à vereadora Marielle Franco, assassinada em março de 2018. Segundo descrito na denúncia apresentada pelo PSOL, Fraga postou em seu Twitter que Marielle havia sido casada com um traficante, eleita com o apoio de uma facção criminosa e era usuária de drogas. Em seguida o mesmo teria feito um post de cunho racista ainda em referência à vereadora. A denúncia relata também que, em entrevista, o deputado não apenas não desmentiu as referidas postagens como afirmou que, apesar de não ter averiguado as informações que disseminou, não se arrependia do que havia dito.

Tal como afirmam Patrícia Donat e John D’Emilio (1992), a violência política de gênero assume um significado adicional como uma forma de aplicação do papel de gênero, um meio de dominação e controle para subordinar as mulheres enquanto grupo. Assim, em que pese a denúncia do PSOL se limite à calúnia, o ataque à condição de mulher e mãe - Fraga também afirmou de maneira crítica que Marielle tinha engravidado na adolescência - fez com que este caso também fosse enquadrado enquanto um episódio de violência política de gênero no qual a mensagem não era voltada à pessoa caluniada, dado que se deu após sua morte, mas às mulheres de maneira mais ampla, configurando-se como uma violência que tem como alvo não apenas aquela que a sofre, mas busca transmitir uma mensagem para as mulheres como um todo.

Este caso, encaminhado para o Coética no dia 27/03/2018, contou desde o início com uma tramitação atípica, pois em menos de um mês três deputados designados relatores declinaram da função. ${ }^{8}$ O parecer apresentado pelo relator, tal como em todos os outros casos aqui abordados, defendeu o arquivamento da denúncia. Adilton Sachetti argumentou em seu voto que 0 representado estaria protegido pela imunidade parlamentar e, portanto, não seria passível de sanções disciplinares nesse caso. Seguindo a linha apresentada pela defesa, o relator finalizou o voto afirmando que o acusado foi, na verdade, uma vítima de uma Fake News.

Durante o processo de tramitação o deputado Pompeo de Mattos apresentou voto em separado, mas em seguida o retirou. O parecer de Sachetti pelo o arquivamento foi aprovado com 10 votos a 1 .

\section{Conclusões}

Argumenta-se que, dada a quase completa ausência de mulheres no processo de tomada de decisões do Conselho de Ética da Câmara dos Deputados, estas decisões poderiam, nos termos trazidos por Jane Mansbridge (2009), ser consideradas injustas, bem como pouco democráticas, dado que permitiriam que uma maioria oprimisse uma minoria. Talvez fosse o caso de se pensar em medidas suplementares, tal como aponta Madison na citação que abre este texto, para controlar a ação daqueles que detêm a autoridade sobre outros homens, nesse caso, mulheres.

O caso do Conselho de Ética da Câmara poderia ser considerado mais um exemplo do fracasso da promessa da democracia representativa idealizada pelos liberais em ser responsiva, bem como proteger e respeitar as minorias, o que torna ainda mais pertinente o debate realizado por Anne Phillips (2001). A autora defende a centralidade da observação das demandas por presença política de grupos que começam a se reconhecer como marginalizados, silenciados ou excluídos, como critério democrático, importante reenquadramento dos problemas da igualdade política na contemporaneidade.

Seguindo o mesmo caminho, Mansbridge (2009) afirma que a deliberação só pode se dar de maneira justa caso não seja unilateral, e, portanto, é necessário que minorias sociais sejam incluídas nesses espaços para que novas perspectivas possam ser inseridas no debate e influenciem na tomada de decisão.

Para Nancy Fraser (2006), o não reconhecimento e a subordinação de status se dão quando padrões institucionalizados de valor cultural constituem alguns atores como inferiores, excluídos ou invisíveis. Nesse sentido, a ausência de reconhecimento implica uma relação institucionalizada de violação da justiça que impede que a pessoa participe de forma paritária na sociedade. Assim, a violência política de gênero, aliada ao histórico de exclusão das mulheres da esfera pública e aos símbolos com os quais ainda hoje essas são identificadas, pode estar limitando a atuação dessas parlamentares, situação agravada pela constatação chegada até aqui de que o Conselho de Ética não cumpre a função de zelar pela ética e dignidade parlamentar, ao menos não cumpriu nos casos analisados.

\footnotetext{
${ }^{8} \mathrm{Em} 10$ de abril de 2018 o Deputado Benjamin Maranhão (PMDB-PB) foi designado relator, dois dias depois declinou da relatoria; no dia 18 de abril o deputado Thiago Peixoto (PSD/GO) foi designado relator, tendo declinado na posição no dia seguinte; em 24 de abril o deputado Adilton Sachetti (PRB-MT) assumiu a relatoria.
} 


\section{Referências}

ÁlVARES, Maria Luzia Miranda. "A questão de gênero e a violência doméstica e sexual". AmazôniaIPAR - Revista Teológico-Pastoral, Belém-PA, p. 25-30, 2003. Disponível em http://www.ufpa.br/ projetogepem/administrator/questaodegenero.pdf. Acesso em 18/07/2013.

BARDALL, Gabrielle. "Gender-Specific Election Violence: The Role of Information and Communication Technologies". Stability: International Journal of Security \& Development, v. 2, n. 3, p. 1-1 1, 2013.

BEAUVOIR, Simone de. O segundo sexo. Tradução de Sérgio Milliet. Rio de Janeiro: Nova Fronteira, 1980.

BIROLI, Flávia. "Violência política contra as mulheres". Blog da Boitempo, 2016. Disponível em https://blogdaboitempo.com.br/2016/08/12/violencia-politica-contra-as-mulheres/. Acesso em 20/ $03 / 2018$.

BOURDIEU, Pierre. O Poder Simbólico. Tradução de Fernando Tomaz. Rio de Janeiro: Bertrand Brasil, 2007.

BRASIL. Código de Ética e Decoro Parlamentar. Brasília: Câmara dos Deputados, 2002.

BRASIL. Rep. 28/2005. Autor: Partido Liberal. Apresentação: 07/06/2005. Ementa: Representa contra o Deputado Roberto Jefferson, como incurso na previsão do art. 55, inciso I, e $\S 1^{\circ}$ da Constituição Federal, combinado com o art. 240 do Regimento Interno da Câmara dos Deputados, combinado com o art. $4^{\circ}$, inciso I, do Código de Ética e Decoro Parlamentar, pelos fatos que expõe. Dados Complementares: Representação do Partido Liberal (PL) contra o Deputado Roberto Jefferson tendo em vista as declarações sobre o "Mensalão". Brasília: Câmara dos Deputados, 2005. Disponível em https://www.camara.leg.br/proposicoesWeb/fichadetramitacao?idProposicao=288489.

BRASIL. Lei $n^{\circ}$ 11.340, de 7 de agosto de 2006. Brasília: Presidência da República, 2006. Disponível em http://www.planalto.gov.br/ccivil_03/_ato2004-2006/2006/lei/11 1340.htm. Acesso em 07/07/2019.

BRASIL. Rep. 27/2014. Autor: Mesa Diretora da Câmara dos Deputados. Ementa: Representa em face do Senhor Deputado LUIZ ARGÔLO, em razão de procedimento incompatível com o decoro parlamentar. Brasília: Câmara dos Deputados, 2014a. Disponível em https://www.camara.leg.br/ proposicoesWeb/fichadetramitacao?idProposicao $=615609$.

BRASIL. Rep. 36/2014. Autor: Partido dos Trabalhadores, Partido Socialismo e Liberdade, Partido Socialista Brasileiro e outros. Apresentação: 11/12/2014. Ementa: Representação por Quebra de Decoro Parlamentar contra o Deputado Jair Bolsonaro. Brasília: Câmara dos Deputados, 2014b. Disponível em hitps://www.camara.leg.br/proposicoesWeb/fichadetramitacao?idProposicao=840957.

BRASIL. Rep. 02/2015. Continuaçãa da apreciação do parecer preliminar referente ao Processo $\mathrm{n}^{\circ}$ 02, de 2015, Representação n॰ 02, de 2015, do PC do B, em desfavor do Deputado Alberto Fraga [...]. Brasília: Câmara dos Deputados, 2015a. Disponível em https://www.camara.leg.br/internet/ sitaqweb/TextoHTML. asp? etapa $=11$ \&nuSessao $=2627 / 15$ \& hrlnicio $=09: 53 \&$ dtReuniao $=03 / 12 /$ 2015\&dtHorarioQuarto $=09: 53 \&$ dtHoraQuarto $=09: 53 \&$ Data $=03 / 12 / 2015$.

BRASIL. Rep. 03/2015. Brasília: Câmara dos Deputados, 2015b. Disponível em https:// www2.camara.leg.br/a-camara/estruturaadm/eticaedecoro/pareceres/parecer-do-deputadopaulo-azi-rep-03-de-2015-em-desfavor-do-dep-roberto-freire.

BRASIL. Rep. 10/2016. Brasília: Câmara dos Deputados, 2016. Disponível em https:// www2.camara.leg.br/a-camara/estruturaadm/eticaedecoro/pareceres/parecer-preliminar-do-depmauro-lopes-relator-do-processo-no-09-16-referente-a-representacao-no-10-16-em-desfavor-dodep-laerte-bessa.

BRASIL. Rep. 18/2017. Brasília: Câmara dos Deputados, 2017. Disponível em https://www.camara.leg.br/ proposicoesWeb/prop_mostrarintegra;jsessionid $=2203$ D453FC1A143D9175B8290D80BDFC. proposi coesWeb1 ?codteor $=1598517$ \&filename $=$ REP $+18 / 2017$.

BRASIL. Rep. 26/2018. Brasília: Câmara dos Deputados, 2018. Disponível em https:// www.camara.leg.br/proposicoesWeb/prop_mostrarintegra;jsessionid = 1354C51422FE4D31551A5B 8CCDBD8EF0. proposicoesWeb2 codteor $=1647934$ \& filename $=R E P+26 / 2018$.

DONAT, Patricia L. N.; D'EMILIO, John. "A Feminist Redefinition of Rape and Sexual Assault". Journal of Social Issues, v. 48, n. 1, p. 9-22, primavera 1992. 
FRASER, Nancy. "Da redistribuição ao reconhecimento? Dilemas da justiça na era pós-socialista". Cadernos de Campo, São Paulo, v. 15, n. 14/15, p. 231-239, 2006.

GRAZZIOTIN, Vanessa. "Violência contra Mulheres na Política: Violência Política de Gênero por Vanessa Grazziotin”. \#AGORAÉQUESÃOELAS. Folha de S. Paulo, 24/1 1/2017. Disponível em http:// agoraequesaoelas.blogfolha.uol.com.br/2017/1 1/24/violencia-contra-mulheres-na-politicaviolencia-politica-de-genero-por-vanessa-grazziotin/. Acesso em 05/03/2018.

IPU. INTER-PARLIAMENTARY UNION. Women in National Parliaments, 2018. Disponível em http:// archive.jpu.org/wmn-e/classif.htm. Acesso em 07/04/2018.

KROOK, Mona Lena; SANÍN, Juliana Restrepo. "Gender and political violence in Latin America". Política y gobierno, v. 23, n. 1, p. 125-157, 2016.

MADISON, James; HAMILTON, Alexander; JAY, John. "Os artigos federalistas". In: Os pensadores. São Paulo: Abril Cultural, 1985. p. 85-178. (v. XXIX)

MANSBRIDGE, Jane. "Should blacks represent blacks and women represent women? A contingent 'yes'”. The Journal of Politics, v. 61, n. 3, p. 628-657, dezembro 2009.

MONTESQUIEU, Charles de. "O Espírito das leis". In: Os pensadores. São Paulo: Abril Cultural, 1985. (v. XXI)

NOBRE, Noéli. "Por unanimidade, Conselho de Ética arquiva representação contra o deputado Roberto Freire". In: BRASIL. "Notícias". Política e Administração Pública, 16/03/2016. Brasília: Câmara dos Deputados, 2016. Disponível em https://www.camara.leg.br/noticias/483232-por-unanimidadeconselho-de-etica-arquiva-representacao-contra-o-deputado-roberto-freire/.

NUNES, Maria do Rosário. "Não Aceitaremos". Agora é que são elas. São Paulo, 2017. Disponível em http://agoraequesaoelas.blogfolha.uol.com.br/201 7/12/1 1/nao-aceitaremos-por-maria-dorosario/. Acesso em 05/03/2019.

PHILLIPS, Anne. "De uma política de ideias a uma política de presença?". Revista Estudos Feministas, Florianópolis, Universidade Federal de Santa Catarina, v. 9, n 1, 2, p. 268-290, 2001.

PEACEWOMEN. Violence Against Women in Politics Surveillance System. Latipur: South Asia Partnership International, 2006. p. 17-23. Disponível em https://www.peacewomen.org/content/violence-againstwomen-politics-surveillance-system.

SCOTT, Joan Wallach. "Gender as a useful category of historical analysis". The American Historical Review, v. 91, n. 5, p. 1503-1075, dezembro 1986.

TAYLOR, Charles. "Multiculturalism and the politics of recognition". In: GUTMANN, Amy (Org.). Multiculturalism: examining the politics of recognition. New Jersey: Princeton University Press, 1992.

TOCQUEVILLE, Alexis de. A Democracia na América. São Paulo: Martins Fontes, 2004.

WORLD ECONOMIC FORUM. The global gender gap report. Geneva: World Economic Forum, 2017.

YOUNG, Iris Marion. "Representação política, identidade e minorias". Lua Nova: Revista de Cultura e Política, São Paulo, Centro de Estudos de Cultura Contemporânea (CEDEC), n. 67, p. 139-190, 2006.

Tássia Rabelo (łas.rabelo@gmail.com) possui Graduação em Ciências Sociais, Mestrado e Doutorado em Ciência Política pelo Instituto de Estudos Sociais e Políticos da Universidade do Estado do Rio de Janeiro (IESP). Atualmente é Professora Adjunta do Departamento de Ciências Sociais da Universidade Federal da Paraíba (UFPB). Tem experiência na área de Ciência Política, com ênfase em partidos políticos em perspectiva comparada e gênero e política. 
COMO CITAR ESSE ARTIGO DE ACORDO COM AS NORMAS DA REVISTA

PINHO, Tássia Rabelo de. "Debaixo do Tapete: A Violência Política de Gênero e o Silêncio do Conselho de Ética da Câmara dos Deputados". Revista Estudos Feministas, Florianópolis, v. 28, n. 2, e67271, 2020.

\section{CONTRIBUIÇÃO DE AUTORIA}

Não se aplica.

\section{FINANCIAMENTO}

Não se aplica.

CONSENTIMENTO DE USO DE IMAGEM

Não se aplica.

APROVAÇÃO DE COMITÊ DE ÉTICA EM PESQUISA

Não se aplica.

\section{CONFLITO DE INTERESSES}

Não se aplica.

\section{LICENÇA DE USO}

Este artigo está licenciado sob a Licença Creative Commons CC-BY International. Com essa licença você pode compartilhar, adaptar, criar para qualquer fim, desde que atribua a autoria da obra.

\section{HISTÓRICO}

